\title{
Aproximações Possíveis da Terapia Focada na Solução aos Contextos Grupais
}

Approaches Of The Solution Focused Therapy In Group Work

Aproximaciones Posibles De La Terapia Focalizada En La Solución A Los Contextos Grupales

Emerson Fernando Rasera \& Pedro Pablo Sampaio Martins

Universidade Federal de Uberlândia

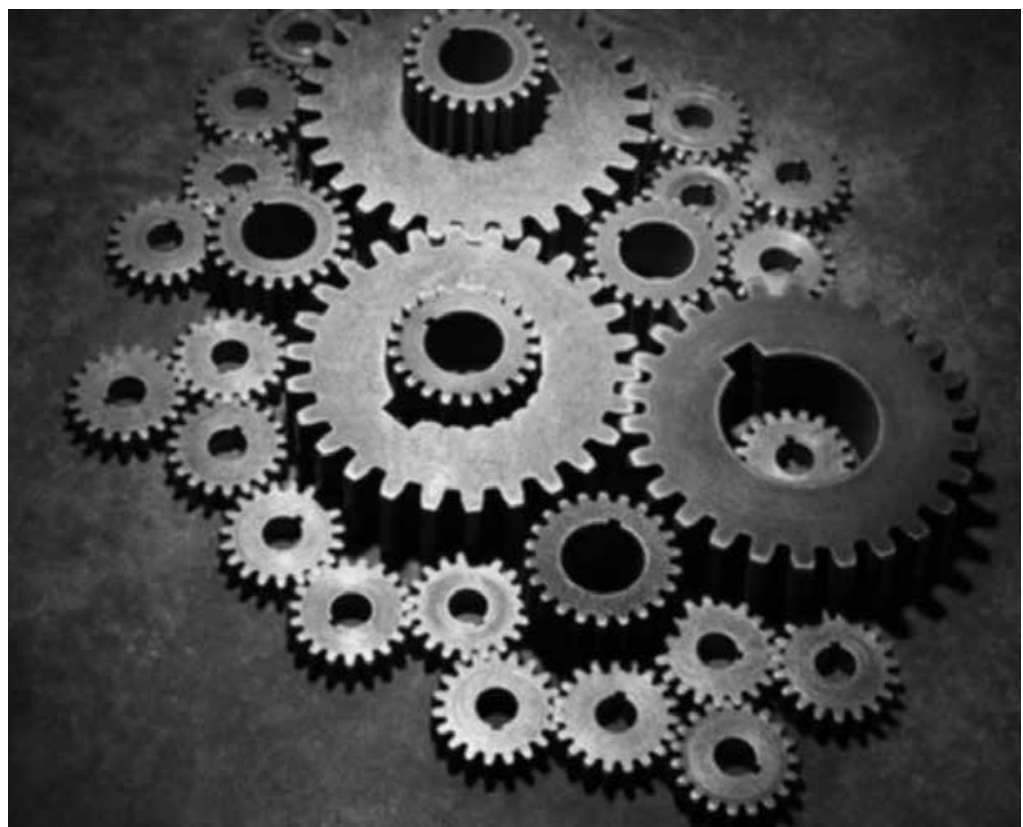


Resumo : A terapia focada na solução (TFS) é um tipo de terapia breve que propõe não ser necessário entender um problema para resolvê-lo. Estabelecendo metas concretas, terapeuta e cliente buscam exceções ao problema, forças e recursos que ajudem o cliente a construir uma vida mais satisfatória para si mesmo. Considerando a fertilidade dessa proposta terapêutica, o objetivo deste trabalho é analisar as possibilidades de utilização das contribuições da TFS no contexto grupal. A análise da incipiente literatura da área mostra que há trabalhos que envolvem diferentes grupos de pacientes que buscam utilizar-se de técnicas da TFS. Buscando aprofundar essa reflexão, analisamos duas propostas significativas nesse campo, as de Metcalf e Sharry. Ambos se valem de conceitos teóricos e técnicos da TFS em contextos grupais assim como apresentam inovações. A análise da visão de grupo sustentada por essas propostas indica uma marca individualista em Metcalf, enquanto Sharry o vê como uma entidade em seu próprio direito, que busca coesão e metas grupais. Uma análise crítica dessa literatura, contudo, aponta um viés tecnicista e, em consequência, a necessidade de maior elaboração teórica para sua efetiva contribuição à prática grupal.

Palavras-chave: Psicoterapia de grupo. Solução de problemas. Psicoterapia breve. Saúde mental.

\begin{abstract}
The solution-focused therapy (SFT) is a kind of brief therapy which states that in order to solve a problem, it's not necessary to understand it. Starting with the establishment of concrete goals, therapist and client search for exceptions to the problem and for the client's strength and resources which may help him build a more satisfying life. Considering the richness of this therapeutic model, this paper aims to analyze the possibilities of using SFT in group contexts. The review of the literature points to the use of SFT in different patient groups. In order to discuss these ideas, we analyzed two important models in this field: Metcalf's and Sharry's. Both authors use theoretical and technical concepts of SFT in group contexts and also present innovative contributions. The analysis of their view of group work indicates that Metcalf considers the group in an individualist perspective while Sharry takes it as an entity in its own right, looking for group cohesion and goals. A critical analysis of the literature points to a technicist bias on these models, and, consequently, a need of theoretical elaboration to make its contribution effective in the group work field.
\end{abstract}

Keywords: Group psychotherapy. Problem solving. Brief psychotherapy. Mental health.

Resumen: La terapia focalizada en la solución (TFS) es un tipo de terapia breve que propone no ser necesario entender un problema para resolverlo. Estableciendo metas concretas, terapeuta y cliente buscan excepciones al problema, fuerzas y recursos que ayuden al cliente a construir una vida más satisfactoria para sí mismo. Considerando la fertilidad de esa propuesta terapéutica, el objetivo de este trabajo es analizar las posibilidades de utilización de las contribuciones de la TFS en el contexto grupal. El análisis de la incipiente literatura del área muestra que hay trabajos que involucran diferentes grupos de pacientes que buscan utilizar las técnicas de la TFS. Buscando profundizar esa reflexión, analizamos dos propuestas significativas en ese campo, las de Metcalf y Sharry. Ambos se valen de conceptos teóricos y técnicos de la TFS en contextos grupales así como presentan innovaciones. El análisis de la visión de grupo sostenida por esas propuestas indica una marca individualista en Metcalf, mientras Sharry lo ve como una entidad en su propio derecho, que busca cohesión y metas grupales. Un análisis crítico de esa literatura, sin embargo, apunta un sesgo tecnicista y, en consecuencia, la necesidad de una mayor elaboración teórica para su efectiva contribución a la práctica grupal.

Palabras clave: Psicoterapia de grupo. Solución del problema. Psicoterapia breve. Salud mental.

A terapia focada na solução é uma forma de terapia breve surgida nos Estados Unidos por volta da década de 80, com os estudos de Steve de Shazer $(1985,1988)$. Suas influências passam pelos trabalhos de Milton Erickson (Erickson, Rossi \& Rossi, 1976) até ideias pós-estruturalistas, tendo sido desenvolvida dentro do campo da terapia familiar sistêmica. Nesse campo, ela está associada a uma perspectiva pós-moderna, que adota uma visão performática da linguagem, abandonando definições essencialistas de personalidade e de psicopatologia. Essa terapia tem como chave central a utilização dos recursos trazidos pelo próprio cliente para responder às suas necessidades e atingir seus objetivos de uma forma que possa chegar a ter uma vida satisfatória para si mesmo tão rápido quanto possível. Esse tipo de terapia alcançou vários desenvolvimentos teóricos, e agregou uma série de pesquisadores e profissionais em torno de suas propostas epistemológicas e técnicas, especialmente no atendimento a famílias. 
Além da terapia familiar, surgiram algumas iniciativas no campo da terapia de grupo. De maneira geral, elas se valem de ferramentas das propostas originais da terapia focada na solução para a sua utilização em contextos grupais; são tentativas realizadas no atendimento a populações específicas, tais como pacientes portadores de HIV (Froerer, Smock, \& Seedall, 2009), pessoas que abusam de substâncias (Mccollum, Trepper, \& Smock, 2003; Smock et al., 2008), adolescentes com problemas escolares (Newsome, 2004) e casais (Nelson \& Kelley, 2001; Zimmerman, Prest, \& Wetzel, 1997), dentre outros.

Alguns trabalhos nessa área se limitam à apresentação de exercícios práticos para a utilização em grupo (Fiske \& Zalter, 2005a, 2005b). Outros misturam a terapia focada na solução com outros tratamentos em grupo, tais como Grandison (2007), que a combina com uma técnica chamada Eye Movement Desensitisation and Reprocessing (EMDR), de LaFountain (1996), que a utiliza em um modelo junto à psicoterapia individual de Adler, e ainda de Springer e Orsbon (2002), em cujo modelo a terapia focada na solução é uma dentre outras quatro teorias de sustentação.

Encontramos, ainda, propostas sistematizadas que se preocupam em pensar sobre maneiras de levar a terapia focada na solução à pratica grupal de um modo mais generalizado do que para grupos específicos. Duas delas são breves apresentações, em artigos (Banks, 2005; Quick \& Gizzo, 2007), enquanto outras duas consistem de livros inteiros que abordam o tema e que trazem uma visão mais elaborada e abrangente sobre tal aproximação, quais sejam, a terapia de grupo focada na solução, proposta por Metcalf (1998), e o trabalho de grupo focado na solução, de Sharry (2001).
Contudo, essas aproximações da terapia focada na solução para um enfoque grupal se desenvolveram, de forma significativa, apenas na última década, e têm um caráter ainda pioneiro, sem esforços de revisão e de reflexão crítica sobre o modo como os conceitos da TFS têm sido utilizados no contexto grupal. No contexto brasileiro, há uma escassez quase completa de literatura em português tanto a respeito da terapia focada na solução quanto de sua utilização em contextos de grupo, o que dificulta o acesso dos profissionais às contribuições dessa proposta terapêutica.

A partir de tais necessidades e motivado pela criação de alternativas pós-modernas para as práticas grupais no Brasil, o objetivo deste artigo é analisar as possibilidades de utilização das contribuições da terapia focada na solução no contexto grupal. Especificamente, buscaremos: a) apresentar os principais conceitos referentes a essa perspectiva terapêutica, b) descrever as propostas grupais influenciadas por suas contribuições, especialmente, a terapia de grupo focada na solução (Metcalf, 1998) e o trabalho de grupo focado na solução (Sharry, 2001), c) analisar a tradução teórico-técnica realizada na construção de cada uma delas a partir das ideias de de Shazer, e d) refletir criticamente sobre as visões de grupo sustentadas por tais propostas e os desafios presentes na aproximação da TFS a esse contexto da prática psicológica.

\section{Terapia focada na solução: pressupostos e técnicas}

A terapia focada na solução começou a desenvolver-se nos Estados Unidos, no Centro de Terapia Familiar Breve (Brief Family Therapy Center - BFTC), quando de Shazer e seus colegas se propuseram a sistematizar um modelo teórico que conseguisse explicar como o terapeuta 
$1 \mathrm{O}$ termo mal-entendido (misunderstanding), neste contexto, refere-se à ideia de que o sentido das coisas não está dado a priori e, portanto, não pode simplesmente ser entendido; pelo contrário, é por meio da negociação entre pessoas interagindo que esses sentidos são criados e, dessa forma, somente um mal-entendido se faz possível. Esse mesmo mal-entendido deve ser utilizado criativamente em terapia para o desenvolvimento do jogo de linguagem focado na solução que possibilita processos de negociação nos quais novas histórias a serem contadas e mudanças no enredo das narrativas dos clientes possam surgir para que vidas mais satisfatórias venham a ser construídas.

\footnotetext{
2 Todas as citações diretas apresentadas neste texto são de tradução dos autores deste artigo.
}

breve agia no contexto terapêutico. Houve ainda outros autores que participaram do processo de desenvolvimento da terapia focada na solução (Berg \& de Shazer, 1993; O'Hanlon \& Davies, 1994), que continua em constante processo de transformação, nem sempre seguindo os mesmos caminhos segundo diferentes autores. Dessa maneira, escolhemos trabalhar com esse modelo como sustentado por de Shazer (1985, 1988, 1991, 1994) devido ao fato de ele ter sido seu criador e nome de destaque sempre que se refere a esse modelo teórico.

de Shazer (1988) afirma que a teoria criada por ele é apenas uma descrição possível dos caminhos que cliente e terapeuta podem usar para se moverem das queixas até metas e soluções. Assim, ele se afasta das ideias positivistas de busca pela verdade e coloca sua teoria como uma possibilidade de entendimento e de busca por soluções.

A terapia focada na solução surge a partir da ideia de que, a fim de se solucionar um problema, não é preciso que se entenda como ele funciona. Que se faça alguma coisa diferente, em uma situação problemática pode ser o suficiente para levar a uma solução. A terapia é vista como um sistema propositado, não sendo possível uma separação entre observador e fenômeno observado - o subsistema do terapeuta, o subsistema do cliente, o problema a ser resolvido e/ou a solução a ser desenvolvida e as suas interações são todos parte do sistema sob consideração.

O foco na solução característico desse modelo teórico é traduzido para a relação terapeuta-cliente por meio do conceito de cooperação, em lugar do tradicional conceito de resistência. De Shazer (1985) considera que a metáfora da resistência não seja útil: se alguém se dispõe a procurar terapia, então o terapeuta deve acreditar sem questionamento que essa pessoa queira mesmo alguma ajuda. Muitas vezes, o terapeuta apenas não encontrou ainda a forma de promover cooperação no relacionamento para a busca de uma solução para a queixa que iniciou o sistema terapêutico. De Shazer (1991) explica mais claramente como entende a relação terapêutica no seguinte trecho:

A relação terapêutica é um esforço negociado, consensual e cooperativo no qual o terapeuta focado na solução e o cliente produzem juntos variados jogos de linguagem focados em (a) exceções, (b) metas e (c) soluções. Todos esses são negociados e produzidos enquanto terapeutas e clientes mal-entendem ${ }^{1}$ juntos, fazem e dão sentido a eventos, sentimentos e relacionamentos de outra forma ambíguos. Ao fazer isso, terapeutas e clientes atribuem juntos sentido a aspectos das vidas dos clientes e justificam ações com a intenção de desenvolver uma solução (p. 74)²

É interessante observar que, nesse processo, refere-se sempre a uma solução, em vez de a solução: não se pressupõe que seja a única ou a melhor - trata-se apenas de uma que se ajusta (fits) à construção da queixa naquele momento. Enfatiza-se exaustivamente que não há necessidade de que o terapeuta consiga uma correspondência (match) entre a realidade que é descrita no contexto terapêutico e a realidade que o cliente de fato esteja vivendo. Tudo o que se faria necessário seria um ajuste da intervenção proposta à construção da queixa. Metaforicamente, "não há necessidade de tentar entender a fechadura a fim de construir uma chave efetiva quando uma chave-mestra pode também funcionar" (de Shazer, 1985, p. 61). Daí surge a possibilidade de a terapia ser breve e, ainda assim, efetiva, uma vez que descrições detalhadas da queixa se tornam dispensáveis. A partir dessa ideia, de Shazer lança mão de diversos recursos e ferramentas que podem ser úteis como caminho para esse objetivo.

Uma dessas maneiras é a criação de expectativa de mudança durante a conversa 
"nada acontece sempre, nada é sempre o mesmo" (de Shazer, 1985, p. 161) terapêutica, com a procura por futuros preferidos do cliente - descrições daquilo que estará presente, ou seja, o que ele estará concretamente fazendo, se a queixa que o trouxe para a terapia estiver ausente. Essas são as metas, e elas informam quando o sistema terapêutico poderá ser dissolvido. Se a queixa do cliente é razão suficiente para começar a terapia, então sua afirmação de melhora satisfatória deve ser suficiente para terminá-la. De outra maneira, a terapia poderia continuar indefinidamente. $\mathrm{Na}$ definição das metas, está presente a ideia de que a mudança é inevitável e que o uso de linguagem pressuposicional por parte do terapeuta contribui para sua construção. Como exemplo, podemos citar o uso da palavra quando, em vez de se, ao se perguntar pelo futuro do cliente ("Quando sua vida estiver melhor..." e não "Se sua vida estiver melhor...").

Muitas vezes, os clientes não sabem exatamente o que procuram na terapia. Como forma indireta de perguntar sobre metas e de ajudá-los a imaginar futuros preferidos, foi desenvolvida a chamada pergunta do milagre, que pode ser anunciada, dentre as variações necessárias de acordo com o contexto, dessa forma: "Suponha que uma noite, enquanto você estava adormecida, houve um milagre e este problema tenha sido resolvido. Como você saberia? O que estaria diferente? Como seu marido saberá, sem você dizer uma palavra para ele sobre isso?" (de Shazer, 1988, p. 5).

Outra maneira prática de focar no presente e no futuro, e implicitamente criar expectativa de mudança, é a utilização da tarefa-fórmula de primeira sessão, cujo enunciado, que pode ser adaptado conforme a necessidade, é o que se segue: "Entre agora e a próxima vez em que nos encontrarmos, gostaríamos que você observasse, de forma que possa nos descrever da próxima vez, o que acontecer na sua família que você quer que continue a acontecer' (de Shazer, 1984; de Shazer \& Molnar, 1894b)" (de Shazer, 1985, p.137).

Além do já citado, essa tarefa ajuda também a promover cooperação naquilo que é característica marcante da terapia focada na solução: a busca por exceções. Com a percepção de que "nada acontece sempre, nada é sempre o mesmo" (de Shazer, 1985, p. 161), começou-se a perguntar por aquelas vezes na vida do cliente em que o problema acontecia menos, ou até mesmo não acontecia. Partindo da ideia de que a linguagem constrói a realidade, acredita-se que as perguntas do terapeuta convidem a determinadas respostas e restrinjam outras possibilidades. Ao buscar exceções na conversa terapêutica, é provável que um terapeuta acabe por encontrá-las. Seu trabalho, então, é construir junto ao cliente uma realidade na qual essas exceções passem a ser vistas como primárias na vida do cliente, em lugar do problema, permitindo que elas sejam, então, diferenças que fazem diferença, e não mais diferenças que passam despercebidas, como se estivessem fora do domínio da queixa. Isso torna possível que soluções se desenvolvam com os clientes fazendo mais do que já sabem fazer: tarefas podem ser prescritas a fim de que as exceções e a maneira como acontecem possam ser usadas como forma de continuar (e não de iniciar) a mudança em direção às metas estabelecidas.

Uma última ferramenta de destaque a ser citada são as chamadas perguntas de escala. Elas foram criadas como maneira de usar o mal-entendimento (misunderstanding) por meio dos números, em qualquer momento que o terapeuta achar necessário, seja para medir a percepção do cliente de quanto ele avançou em direção à meta ou para qualquer outra finalidade que o terapeuta julgar útil. Inicialmente, elas consistiam na pergunta do terapeuta ao cliente em qual ponto, em uma escala de 1 a 10 , ele se encontrava naquele dado momento com relação à sua 
meta, mas podem ser adaptadas de acordo com a situação. Diferentemente de uma escala baseada em padrões normativos, as perguntas de escala funcionam simplesmente para ajudar a conversa terapêutica a andar de variadas maneiras conforme o contexto, e são bastante utilizadas por de Shazer (Berg \& de Shazer, 1993).

Como vemos, de Shazer $(1985,1988)$ propõe um modelo de terapia cuja intenção é fazer que o processo terapêutico possa ocorrer de modo mais breve possível, em um esforço conjunto de cliente e terapeuta, guiados por metas claras e bem estabelecidas e que, por meio da utilização das ferramentas técnicas propostas e dos recursos trazidos pelo próprio cliente, este possa construir uma vida que considere mais satisfatória naquele momento.

\section{Grupos e terapia focada na solução}

Buscando compreender de que forma a terapia focada na solução tem sido utilizada no contexto grupal, analisaremos duas propostas sistemáticas e amplas de utilização de seus princípios e técnicas nesse contexto, quais sejam, a terapia de grupo focada na solução, proposta por Metcalf (1998), e o trabalho de grupo focado na solução, de Sharry (2001). Por meio de sua apresentação, buscaremos analisar como estão presentes os principais fundamentos teóricos e epistemológicos, o entendimento sobre o funcionamento das sessões, as ferramentas técnicas inspiradas pela terapia focada na solução bem como as diferenças ou as inovações com relação ao pensamento de Shazer (1985, 1988, 1991, 1994).

\section{Terapia de grupo focada na solução}

A terapia de grupo focada na solução é uma proposta terapêutica descrita por Linda Metcalf (1998). Essa autora é uma terapeuta americana que trabalhava com tratamento de grupo para variados problemas mentais utilizando-se de modelos teóricos tais como terapia estratégica, terapia estrutural e terapia de família-de-origem, quando decidiu começar a integrar em seus grupos ideias advindas da terapia focada na solução.

Os grupos focados na solução facilitados por Metcalf são orientados para a chamada conversa de solução, seguindo a premissa básica de que os clientes são pessoas competentes e precisam apenas de uma atmosfera propícia para que possam resolver seus próprios problemas. Para ela, os clientes são pessoas que têm queixas sobre suas vidas em vez de sintomas. Há um abandono da busca por promoção de insight e um objetivo de manter o grupo terapêutico não patológico, ou seja, as conversas devem sempre ser dirigidas para a busca de soluções, oferecendo novas descrições que sejam úteis para os clientes e possam abrir possibilidades.

Terapeuta e cliente são vistos como se estivessem engajados em uma relação de parceria, de forma que os atos de aconselhar e de sugerir estratégias por parte do terapeuta são fortemente desencorajados. A busca por recursos, habilidades e exceções deve acontecer conjuntamente entre terapeuta e cliente, assim como com outros membros do grupo, que são sempre convidados a participar. Essa é uma forma de promover afinidade grupal e aproveitamento, por parte de outros membros do grupo, de estratégias surgidas originalmente para um deles.

A primeira sessão de terapia de grupo focada na solução começa com a apresentação 
dos membros do grupo contando o que acreditam que os outros precisam saber, sem se sentirem obrigados a falar sobre qualquer coisa específica. O objetivo é, desde o começo, criar um clima para que o foco se dê nas soluções. O grupo prossegue com o terapeuta solicitando que os clientes estabeleçam as metas que queiram alcançar durante o processo. O ideal é que essas sejam tão concretas e específicas quanto possível, e é trabalho do terapeuta ajudar os clientes nessa tarefa. Uma forma de se fazer isso é utilizar ferramentas como a pergunta do milagre.

Afora esses passos iniciais, as demais sessões não têm uma estrutura pré-definida e compartilham de características semelhantes, descritas a seguir. Assim, a busca por comportamentos que representem exceções, "eventos reais que ocorrem fora do contexto do problema" (1998, p. 10), como Metcalf usa o termo, deve ocorrer constantemente em toda sessão.

Além disso, a motivação deve ser encorajada sempre. Para tanto, o terapeuta pode conversar de forma tal que fique claro em sua fala sua expectativa genuína de que a mudança ocorra. Convidar os membros do grupo a se juntarem nessa tarefa também é uma estratégia a ser utilizada. Pode-se perguntar a eles, por exemplo: "O que vocês verão este membro do grupo fazendo mais quando o problema se dissolver?" (Metcaf, 1998, p. 60).

Outro ponto do qual o terapeuta deve lembrar-se é o de adotar temporariamente a visão de mundo do cliente, transmitindo ao grupo a ideia de que acredita que os comportamentos atuais de um membro sejam a maneira que ele encontrou de sobreviver até agora e que, portanto, Ihe têm sido úteis. Esse reconhecimento ajudaria a diminuir a resistência do cliente e possibilitaria a procura por outros comportamentos mais positivos e menos prejudiciais que pudessem substituir os primeiros. Metcalf aponta a importância de um terapeuta sempre considerar quais são suas visões a respeito dos membros do grupo, de como as pessoas mudam e do que elas precisam fazer para mudar, pois todas essas são carregadas para o contexto da terapia e influenciarão a forma como o processo ocorrerá.

Aproximando-se do fim de cada sessão, o terapeuta pode encorajar os clientes a pensarem, por uma semana, sobre o que os ajudará a começar a mover-se em direção à meta. Esse é outro aspecto frisado por Metcalf, o de incentivar os clientes a verem cada pequeno passo tentado em direção à solução apenas como um experimento, e não necessariamente como uma estratégia que garantiria o sucesso. Os clientes são encorajados a se mover gradualmente para as soluções e a entender que pequenas mudanças podem trazer alívio e qualidade de vida, e que é por meio delas que metas maiores podem ser alcançadas. A premissa é a de que problemas complexos não necessariamente requerem soluções complexas.

Metcalf (1998) oferece, ainda, uma série de exercícios que podem ajudar o grupo a se mover em direção aos objetivos da terapia, aos quais o terapeuta pode recorrer quando e se julgar necessário. Geralmente, eles consistem de folhas de papel entregues aos clientes com perguntas, checklists, citações ou espaços para completar cujo conteúdo possa ser útil para ajudar o cliente a pensar sobre seu processo. Além disso, ela também recorre a algumas das perguntas criadas por de Shazer, tal como a pergunta do milagre e as perguntas de escala. A respeito do fim do processo grupal, a proposta dessa autora não explicita como acontece.

\section{O trabalho de grupo focado na solução}

O trabalho de grupo focado na solução foi 
Segundo Sharry, "terapia é

idealmente um processo de empoderamento, no qual os clientes são 'reconectados' aos recursos que existem

em suas vidas e encorajados a se encarregar de sua própria cura" (2001, p. 7). desenvolvido por John Sharry (2001), um terapeuta e assistente social irlandês que vem trabalhando em contextos de saúde mental com grupos terapêuticos de crianças, famílias e adultos há muitos anos. Orientado pela ideia de que focar em problemas em terapia não apenas pode ser desnecessário como também contraprodutivo, e pautando-se no arcabouço teórico do construcionismo social, ele apresenta a maneira de utilizar os princípios da terapia focada na solução a grupos terapêuticos.

Segundo Sharry, "terapia é idealmente um processo de empoderamento, no qual os clientes são 'reconectados' aos recursos que existem em suas vidas e encorajados a se encarregar de sua própria cura" (2001, p. 7). Os grupos facilitados por ele têm como característica a procura por certa homogeneidade, de tal maneira que os membros sejam similares o suficiente para se identificarem uns com os outros, mas também diferentes para que possam aprender entre si. A intenção é que se crie coesão grupal, mas que isso aconteça por meio de uma identidade positiva, ou seja, que as pessoas possam encontrar-se tendo como guia metas e futuros preferidos similares aos que desejem chegar, e não problemas ou patologias. Para que se alcance isso, o facilitador desempenha um papel fundamental no início dos grupos, mostrando para os membros que o desejável é que ocorra, na maioria do tempo, a conversa focada na solução, procurando o que está certo e o que está funcionando, por forças, habilidades e recursos dos clientes e pelas exceções ao problema que possam estar passando despercebidas.

O trabalho de grupo focado na solução faz parte do contexto da terapia breve, e pode durar entre uma e doze sessões. De maneira geral, a primeira sessão do trabalho de grupo focado na solução começa com a conversa livre de problemas, um tipo de conversa que lembra um bate-papo social e que tem a intenção de fazer que os clientes possam começar a familiarizar-se com o ambiente e ficarem confortáveis. Isso pode ser feito de maneira estruturada, com algum exercício, ou simplesmente acontecer naturalmente. Em foco proeminente nessa sessão, está o estabelecimento de metas que guiarão o trabalho terapêutico. Os clientes podem revisar e consolidar as metas sobre as quais já haviam conversado na triagem e na entrevista de preparação, sendo esse um momento para aproximar os objetivos de todos, criando metas coletivas para o grupo. Além disso, o método do grupo pode ser renegociado nesse momento junto a todos, assim como as regras fundamentais para seu funcionamento. Essas são as partes mais evidentes na primeira sessão, mas é importante que se inicie minimamente a tarefa para a qual o grupo se reuniu. A pausa terapêutica na sessão, em que o terapeuta faz uma interrupção de alguns minutos e se retira da sala para pensar ou para consultar sua equipe, se houver uma, é utilizada aqui de diversas maneiras, desde marcador para a aproximação do fim da sessão até espaço para os membros do grupo e facilitadores poderem avaliar a sessão e fazerem planos, e acontecerá não só na sessão inicial como também em todas as outras. Após o retorno, os facilitadores podem dar feedback e prescreverem tarefas terapêuticas (como a tarefa-fórmula de primeira sessão, tal qual preconizada por de Shazer (1985)), mas aos clientes deve ser dada a chance de ter a palavra final, para que avaliem como ocorreu a sessão de maneira geral.

As sessões subsequentes têm como foco central o processo dos clientes e podem seguir a técnica EARS (sigla em inglês para elicit, amplify, reinforce e start over) que visa a identificar e a fortalecer as mudanças por meio do processo de eliciar exemplos de progresso, ampliá-los e reforçá-los para, então, começar novamente, procurando por outros exemplos do que está melhor. Tudo isso é feito através da conversa terapêutica e, 
sobretudo, do uso de perguntas construtivas. Valoriza-se aqui uma postura de respeitosa curiosidade. Nessas sessões, é importante que se dê oportunidades para que os clientes possam revisar suas próprias metas e aquelas do grupo, assim como para renegociarem constantemente o método. A ideia é que o ajuste seja sempre desenvolvido junto aos clientes e que seja possível criar cooperação e colaboração na relação terapêutica. Ponto importante a ser ressaltado é a intenção de que os clientes passem a conversar cada vez mais entre si e desenvolvam suas próprias soluções. Sharry (2001) acredita que o papel do terapeuta eventualmente deverá ser apenas "ficar fora do caminho" da conversa, e que os clientes do grupo interajam mais entre si do que com o facilitador.

Quanto à sessão final do grupo, ela tem dois objetivos principais, quais sejam: a) revisar o grupo, de maneira que seus componentes possam pensar sobre suas metas e sobre as mudanças ocorridas entre a primeira e a última sessão, consolidando entendimentos e realizações obtidos durante esse tempo, e b) apoiar e fazer planos para o futuro, para que os clientes possam refletir sobre seus próximos passos, assegurando que os ganhos sejam mantidos e que se previna recaídas. Sharry aconselha que uma parte dessa sessão seja dedicada a feedback dos membros para o facilitador e que haja algum tipo de celebração da mudança, que possa realçar as mudanças positivas e reforçar novas autodefinições. Além disso, segundo ele, pode ser interessante que o grupo possa continuar a reunir-se sem a participação de qualquer facilitador profissional, ou seja, que se torne um grupo de autoajuda gerido por seus próprios membros. Outra ideia, surgida a partir do reconhecimento de que a mudança ocorre fora do processo terapêutico, é a de que haja sessões de revisão ou de seguimento, propiciando um espaço para que as mudanças surgidas após o fim da terapia possam ser eliciadas, ampliadas e reforçadas.
Outro aspecto característico do trabalho de Sharry (2001) é a utilização do bom humor e da criatividade como forma de tornar o grupo terapêutico um ambiente do qual as pessoas gostem de participar, sendo uma exceção aos problemas do cotidiano.

Tendo descrito brevemente essas duas propostas, podemos proceder a uma análise comparativa entre elas, considerando a teoria da terapia focada na solução e de que maneiras suas ideias estão refletidas nos contextos grupais dos quais ambas se propõem tratar.

\section{Diálogos entre a terapia de grupo e o trabalho de grupo focados na solução}

Ao pensarmos em uma comparação entre a terapia de grupo focada na solução e o trabalho de grupo focado na solução, manteremos em vista uma reflexão a respeito de questões como: em que sentido cada uma dessas propostas traduz os conceitos propostos por de Shazer (1985, 1988, 1991, 1994) para contextos grupais? Quais são os conceitos contemplados e quais ficam de fora? Há mudanças no uso desses conceitos? Quanto há de fidelidade ao pensamento do autor e quanto há de inovação em cada proposta? Esta análise não busca a melhor tradução ou a ideia mais correta do autor original, mas procura compreender diferentes possibilidades de usar sua teoria em contextos grupais, reconhecendo as tensões bem como as inovações presentes nas propostas analisadas.

Para começar, devemos abordar as questões teóricas e epistemológicas envolvidas na formulação das duas propostas. É assim que nos perguntamos a respeito de a qual terapia focada na solução cada um deles se refere mais especificamente, isso porque, como já dito no início deste artigo, de Shazer (1985, 
1994) começou seus estudos a partir de uma perspectiva da hipnoterapia ericksoniana, que influenciou bastante seu trabalho, mas da qual foi afastando-se e recorrendo a outros referenciais teóricos, como o pensamento pós-estruturalista, para dar sustentação a sua teoria. É assim que, com a evolução de seu trabalho, um foco mais proeminente na linguagem como construtora do mundo foi sendo desenvolvido (de Shazer, 1994). Por essa razão, autores como Gergen e Warhuus (2001) o colocam junto das terapias chamadas construcionistas sociais. Foge ao escopo deste trabalho uma discussão maior a respeito da evolução da terapia focada na solução como um todo. Entretanto, é preciso que tal evolução seja reconhecida, já que Sharry (2001) se coloca como um autor que busca suas fontes no construcionismo social, enquanto o trabalho de Metcalf (1998) parece dialogar predominantemente com os escritos de Milton Erickson (Erickson, Rossi \& Rossi, 1976).

Associado a isso, está certo viés individualista apresentado por Metcalf (1998), marcado pelas ideias de cognição e de interioridade presentes na recorrência frequente do termo crença em seu trabalho. Para ela, as crenças dos indivíduos a respeito de si mesmos e dos problemas que os perturbam na vida são de central importância no contexto terapêutico, pois são elas que os levam a determinadas ações que, de alguma forma, os têm incomodado. Assim, a autora acredita que o processo terapêutico deva ser guiado no sentido de que as antigas crenças do cliente não sejam fortalecidas e possam ser substituídas por outras mais adequadas para si mesmos. Em contrapartida, não encontramos nos escritos de Shazer(1985, 1988, 1991, 1994) nem de Sharry (2001) quaisquer afirmações a respeito de crenças ou de sua mudança.

Essa influência fica ainda evidente quando se analisa a reação terapeuta-cliente, tal como presente na seguinte passagem:

“Terapeutas de grupo focados na solução têm uma oportunidade única de encorajar seus clientes a se verem diferentemente ao mudarem o contexto do processo de grupo de um foco em problemas para uma tentativa de descobrir soluções que se encontram dentro de cada indivíduo" (Metcalf, 1998, p. 64, grifo nosso)

Nesse trecho, ela se afasta do pensamento de Shazer (1985) a respeito de as soluções serem coconstruídas por paciente e terapeuta, na relação. Comparando, quando recorremos a de Shazer (1985), essa diferença fica clara: "a mudança terapêutica é um processo interacional envolvendo tanto o cliente como o terapeuta" (p. 65). Sharry (2001) parece partilhar dessa ideia, incluindo também nesse processo os outros membros do grupo como coconstrutores das soluções: eles são instigados a apoiar e a encorajar uns aos outros em direção a suas metas similares, podendo contar não somente com seus próprios recursos como também com os de seus colegas de grupo.

A respeito da visão do cliente sustentada por esses autores, Metcalf afirma olhar para seus clientes como "pessoas que têm queixas sobre suas vidas, e não sintomas" (1998, p.16), no que é de perto acompanhada por Sharry, ao dizer que "quando terapeutas focados na solução escutam os clientes, eles estão interessados neles como pessoas à parte do problema" (2001, p. 32). Quanto ao papel do terapeuta, ambos são bastante ativos no processo terapêutico. Com palavras diferentes, cada um dos dois descreve basicamente o mesmo papel: um terapeuta que procura junto ao cliente recursos, forças e exceções, buscando ampliar aquilo de positivo que já está acontecendo na vida do cliente. Existe, entretanto, uma diferença entre os dois: Sharry demonstra uma preocupação com as conversas que ocorrem no grupo para que sejam cada vez menos centradas 
no facilitador e mais nos próprios membros do grupo, de forma que se possa chegar a, eventualmente, continuar sem a presença do profissional. Metcalf não afirma nada a esse respeito, mas, com suas maneiras práticas de proceder, dá a entender que ocupa, na maior parte do tempo, um papel de mediadora e de estimuladora das conversas no grupo.

Diferença marcante a ser notada é a constante referência feita por Metcalf (1998) a formas de se diminuir a resistência do cliente. Se entendermos que, para que seja possível diminuir uma resistência é preciso, primeiro, que a mesma exista, então isso está em desacordo com de Shazer, (1985) que abandonou o conceito de resistência, considerando-o inútil. Para ele, só se vê resistência quando se escolhe olhar para o que acontece na relação quando o cliente não está convencido da maneira como a mudança está sendo proposta para ele. Sob outro olhar, o mesmo terapeuta pode escolher acreditar que não encontrou a maneira de fazer o cliente cooperar e, portanto, que o ajuste não tenha sido alcançado. Esse ponto de vista é compartilhado por Sharry (2001), que insiste na busca por cooperação e colaboração e que enxerga resistência como um processo compartilhado, criado por terapeuta e cliente em relação. Quando isso acontece, cabe ao terapeuta procurar fazer algo diferente que possa mudar o contexto para que se promova a colaboração.

A seguir, é possível refletir a respeito do funcionamento da sessão colocado por esses dois autores. No que se refere ao foco nas soluções, característico desse modelo teórico, ambos guiam seus trabalhos com grupos focando na conversa direcionada para aquilo que está funcionando na vida dos clientes, suas habilidades e recursos, de forma que a solução possa desenvolver-se. Eles reconhecem que, por vezes, é necessário conversar um pouco sobre o problema, mas a intenção é que essa conversa tome apenas uma pequena parte do tempo do grupo. Acredita-se que seja necessário estabelecer um clima no qual os clientes possam acreditar que a mudança é possível, e, para isso, focar no que de melhor acontece em suas vidas é um bom recurso a ser utilizado. Apesar do conceito de exceções aparecer mais frequentemente no trabalho de Metcalf (1998), os dois autores recorrem a ele como parte essencial na busca por soluções. A esse mesmo respeito, percebemos também que nas duas propostas existe o foco no presente e no futuro, sendo o passado revisitado apenas diante da busca de situações e de tempos em que se estava melhor, e como isso pode ajudar o cliente no presente. A intenção é que o grupo seja mantido longe de patologias. Metcalf instrui os terapeutas a direcionarem seus clientes no sentido de evitar a busca por insight e explicações, postura partilhada por Sharry (2001), ao afirmar que se afastou da ideia que tratava da necessidade de se entender e de analisar um problema para que ele pudesse ser solucionado. Tudo isso está em consonância com de Shazer (1985), que recorre à metáfora da chave-mestra para elucidar que, a fim de resolver um problema, não é necessário que se conheça a sua causa: seus estudos junto à equipe do BFTC os levaram a crer que soluções têm pouco a ver com problemas - elas devem apenas se ajustar. Sharry recorre ao conceito de ajuste tal qual explicado por de Shazer, mas esse conceito não aparece explicitamente em Metcalf, apesar de poder ser, de alguma maneira, inferido.

Um aspecto marcante do trabalho de Shazer é o que ele chamou de "apenas arranhar a superfície" ou "chegar à superfície do problema" (1991, 1994), ou seja, que ele limitava suas descrições apenas àquilo que era prontamente observável, sem olhar atrás ou abaixo das palavras, fazendo interpretações, como se houvesse mais ali. Essa característica do trabalho parece ter sido respeitada por Metcalf, quando ela se propõe dizer para 
os clientes, no início de um grupo, que está interessada em saber apenas o que eles pensam que é necessário que ela saiba sobre si mesmos. Ela evita elaborar quaisquer hipóteses, o que pode ser visto como "se mantendo na superfície", tal qual de Shazer (1991, 1994) diria. Apesar de também não apresentar explicitamente essa proposição, Sharry (2001) segue a mesma tendência ao não procurar causas ou explicações para os problemas apresentados pelos clientes.

Outra questão importante é o fato de as duas propostas aqui discutidas terem como parte central do funcionamento de seus grupos o estabelecimento de metas, ponto enfatizado constantemente na obra de de Shazer (1985, 1994): é função do terapeuta ajudar o cliente a pensar sobre o que ele estará fazendo quando a questão que o trouxe para a terapia não for mais um problema. Que essas metas sejam tão concretas quanto possível e bem formuladas, e que a elas se recorra sempre como guia para os rumos que o processo terapêutico toma são características compartilhadas pelos autores. A ideia é de que o cliente deve saber quando a terapia já Ihe foi suficiente, e é necessário que isso possa ser visto por ele mesmo. Ponto de inovação a ser reconhecido na proposta de Sharry (2001) é a formulação de metas coletivas comuns para o grupo, que devem ser sempre realçadas e relembradas, o que ajuda a promover a coesão.

Tanto Sharry (2001) quanto Metcalf (1998) se valem bastante das contribuições de de Shazer em se tratando da utilização de determinadas ferramentas durante o processo terapêutico. É assim que, por exemplo, ambos recorrem à pergunta do milagre como forma de possibilitar que os clientes formulem metas concretas para a terapia. No caso de Sharry, ele enfatiza que metas grandes e irrealistas, mas que são importantes para os clientes, podem ser muito motivadoras e não devem ser desencorajadas. Entretanto, uma vez que tenham sido entendidas e apoiadas, é preciso que se passe à negociação de outras metas menores às quais se possa chegar na terapia. Isso vai ao encontro do que Metcalf faz, ao encorajar e validar pequenas mudanças como maneiras de se chegar à meta final do cliente. Além disso, ela convida os outros membros do grupo a sugerirem para o colega comportamentos adicionais que acreditam que estarão acontecendo quando ele estiver se sentindo melhor em sua vida.

Os dois autores usam também as perguntas de escala, criadas por de de Shazer (Berg \& de Shazer, 1993), das mais diversas maneiras. Uma delas é a de dividir a meta maior em várias partes com as quais fica mais fácil lidar. Outra maneira é usá-las a fim de que os membros do grupo possam avaliar seu próprio progresso em direção à meta. Essa é uma oportunidade para o terapeuta reconhecer habilidades e recursos, perguntando o que um membro específico do grupo fez para conseguir chegar até o número por ele respondido, e não a um mais baixo.

Informados pela noção de que "chamar algo de 'problema'" é apenas uma de muitas maneiras que as pessoas podem usar para dar sentido ao que acontece em suas vidas" (de Shazer, 1988, p. 12) e que o uso do malentendido no jogo lingüístico possibilita a construção de diferentes e novas realidades - mais satisfatórias para o cliente, Metcalf (1998) e Sharry (2001) procuram buscar novas descrições para os problemas dos clientes do grupo. Ela discorre, por diversas vezes, sobre a redescrição de problemas para abrir novas possibilidades, como, por exemplo, quando propõe a mudança de descrição de clientes que sofreram abuso sexual de vítimas para sobreviventes como maneira de começar grupos com essas pessoas, ou ainda ao redescrever comportamentos que aparecem na literatura científica como doenças (como transtornos alimentares e uso e abuso de 
drogas), como hábitos que temporariamente incapacitaram a vida dessas pessoas. Sharry, por sua vez, usa a técnica de reenquadre, acreditando que

uma nova descrição ou metáfora pode reduzir a influência de um problema realçando-se outros aspectos saudáveis da vida do cliente ou de fato revelando uma força escondida ou benefício dentro do problema. Quando as coisas são vistas diferentemente, elas podem se tornar recursos na criação de uma solução (...) (2001, p. 25)

Além disso, os grupos de Sharry são marcados por uma pausa terapêutica perto do final da sessão, tal como acontece na terapia feita por de Shazer. Os facilitadores do trabalho de grupo focado na solução podem pedir que os membros do grupo fiquem em duplas ou trios refletindo sobre aquela sessão, enquanto discutem entre si. Por vezes, ao voltarem, eles recomeçam com feedback construtivo para os clientes e podem dar sugestões de tarefas para os membros do grupo, exatamente como os elogios feitos por de Shazer (1988) àquilo que notara que o cliente fazia de bom para si mesmo, utilizados como maneira de criar cooperação para sugerir a tarefa que se seguiria. Já Metcalf (1998) não estrutura o funcionamento de seus grupos dessa maneira específica: ela propõe que o terapeuta comente sempre que notar habilidades, forças, recursos e competências de um membro do grupo e convide os outros membros a partilharem sua opinião sobre $\mathrm{o}$ mesmo. Quanto às tarefas, ela incentiva os clientes a criarem suas próprias, de maneira que o objetivo da tarefa fica sempre claro para o cliente e que o tempo entre dois encontros do grupo seja aproveitado.

Metcalf e Sharry parecem ainda se beneficiar do conhecimento trazido por de Shazer relativo ao fato de que, a fim de que a mudança aconteça, é preciso que se crie o clima para isso, a expectativa da mudança. Para essa finalidade, Sharry utiliza a tarefa-fórmula de primeira sessão tal qual preconizada por de Shazer (1985). Metcalf (1998), apesar de não usar a mesma ferramenta, recorre em sua entrevista de admissão a outro recurso de que de Shazer (de Shazer, 1991) lançava mão, que é o uso de um vocabulário que já coloca para o cliente que ela espera que a mudança aconteça, a chamada linguagem pressuposicional.

Aspecto em que Metcalf e Sharry parecem inovar juntos, utilizando a contribuição de outro autor, que não Steve de Shazer, está presente na utilização de uma técnica advinda da terapia narrativa, chamada externalização do problema, criada por Michael White (White \& Epston, 1990), e que tem como finalidade redescrever um problema como uma entidade externa ao cliente, que perturba sua vida, separando linguisticamente um do outro. Isso tem o efeito, segundo os autores, de ajudar os clientes a se sentirem capazes de intervir em suas próprias vidas. Apesar de essa técnica ser utilizada por ambos, Metcalf (1998) Ihe dá um lugar de destaque no curso de seus escritos, enquanto Sharry (2001) apenas passa brevemente por ela.

A última contribuição a ser citada é o processo de avaliação do grupo criado por Sharry, que vai ao encontro das preocupações de Shazer (1985, 1991) em se certificar sempre se a terapia está sendo produtiva. Aquele autor desenvolveu um protocolo de avaliação para grupos em andamento, com o objetivo de manter o grupo focado na solução, que consiste de formulários de medidas de realização de metas, medidas psicométricas padronizadas, formulários de avaliação de processo de cada sessão e seguimento, aplicados em pontos estratégicos no transcorrer do grupo. Metcalf (1998), apesar de demonstrar um interessante similar e ter alguns questionários que parecem buscar o mesmo objetivo, não o faz de forma tão sistematizada. 
De forma resumida, as comparações acima apresentadas podem ser vistas na Tabela 1.

Tabela 1. Comparação entre as propostas da terapia de grupo focada na solução e o trabalho de grupo focado na solução

Terapia de grupo focada na solução Metcalf (1998)

Questões teóricas e epistemológicas

Funcionamento das sessões

Ferramentas utilizadas
Trabalho de grupo focado na solução Sharry (2001)

\section{- Influenciada}

predominantemente pela hipnose ericksoniana.

- Terapeuta tem como função se engajar junto ao cliente na busca por exceções, forças e recursos.

- Recorre ao conceito de resistência, visando a diminuí-la e a promover a cooperação do cliente.

- Foco na conversa de solução, voltada para o presente e o futuro.

- Busca por exceções.

- Promove a não patologização do grupo.

- Abandona a busca por insights e explicações, procurando "apenas arranhar a superfície".

- Trabalha com o estabelecimento de metas para cada um dos participantes.
- Influenciado predominantemente pelo construcionismo social.

- Terapeuta tem como função identificar e ampliar mudança positiva que já esteja acontecendo, além de tornar o grupo independente de si.

- Abandona o conceito de resistência, procurando cooperação e colaboração na relação.

- Foco na conversa de solução, voltada para o presente e o futuro.

- Busca por exceções.

- Promove a não patologização do grupo.

- Não busca entender nem analisar problemas, procurando "apenas arranhar a superfície".

- Trabalha com o estabelecimento de metas para cada um dos participantes, bem como para o grupo como um todo.

- Perguntas do milagre.

- Perguntas de escala.

- Reenquadre.

- Elogios.

- Tarefa-fórmula de primeira sessão.

- Pausa terapêutica na sessão.

- Tarefas entre as sessões.

- Externalização do problema.

- Recorre ao conceito de crenças.
- Externalização do problema.

- Protocolo de avaliação do grupo. da terapia focada na solução

- Tarefas entre as sessões. Shazer

- Perguntas do milage.

- Redescrição de problemas.

- Elogios.

- Uso de linguagem pressuposicional.

Diferenças com de 
Enfim, percebemos que existe certa semelhança na forma como os dois autores escolhem trabalhar. Eles recorrem a muitos dos mesmos conceitos e ferramentas propostos por de Shazer e parecem procurar utilizar em seus grupos a terapia focada na solução tal como ensinada por ele. Entretanto, existem também diferenças, já que nenhum dos dois contempla toda a obra do autor, privilegiando determinados conceitos em detrimento de outros.

\section{De quais grupos se fala?}

Após esta comparação conceitual e técnica entre as propostas de aproximação da terapia focada na solução a contextos grupais sugeridas por Metcalf (1998) e Sharry (2001), procuraremos entender quais são as visões de grupo subjacentes à proposta de cada um dos autores e o quanto as mesmas são consideradas de forma específica para grupos.

Começando por Metcalf, ao procurarmos em que fontes de teoria de grupo a autora busca seus embasamentos, não é possível encontrar claramente essas referências. Ela mostra sua visão de como um grupo pode ser importante e eficiente: para ela, o grupo focado na solução apresenta a oportunidade de as pessoas encontrarem "um lugar confortável no mundo, um lugar no qual seus problemas não parecem tomar conta" (1998, p. 5). Ela acredita que "pertencer a um grupo parece nos trazer um senso de importância, aceitação, suporte e validade em nossas vidas - algo que nós não podemos sempre alcançar sozinhos" (1998, p. 36), e que esse contexto cria o ambiente propício para que as pessoas tenham permissão e validação para tentar novas estratégias. Fica claro nessas descrições que, em seus grupos, as pessoas são chamadas e encorajadas a participar com palpites e opiniões no processo terapêutico dos outros membros - seja evidenciando seus aspectos positivos, seja ajudando no estabelecimento de metas ou apenas compartilhando aspectos parecidos de suas histórias e que podem criar um senso de que as pessoas não estão sozinhas no mundo com seus problemas. Maiores considerações teóricas, entretanto, não parecem ser sua preocupação, e fica difícil inferir com que autores ela dialoga a respeito de processos grupais.

Sharry (2001), por outro lado, explica que o seu trabalho de grupo focado na solução foi influenciado, no que se refere à perspectiva grupal, pela literatura sobre grupos de autoajuda. Nesse sentido, ele afirma não estar desenvolvendo um novo modelo de trabalho de grupo, mas respondendo a um clima atual que reflete um crescente interesse em intervenções mais breves e baseadas em recursos e potencialidades. Ainda segundo o autor, os grupos de autoajuda, tal como o Alcoólicos Anônimos (AA), começaram a ganhar ressonância nos anos 80 e 90, e há uma série de sobreposições e paralelos possíveis entre esses modelos e aqueles de terapia breve, uma vez que "ambos demonstram o valor crescente colocado em clientes resolvendo problemas a partir de suas próprias forças, como oposto a ser dependente de um facilitador profissional." (2001, p. 5). Mais ainda, Sharry se vale dessa fonte ao propor que, idealmente, todo grupo focado na solução deveria transformar-se em um grupo de autoajuda, deixando de depender do facilitador. Esse autor, embasado pelas ideias de Yalom (1970 como citado em Sharry, 2001), acredita que o grupo seja uma entidade própria, detentor de identidade e de características próprias, diferentes daquelas de seus membros individuais e no qual existem fatores terapêuticos inerentes, surgidos das interações entre os membros do grupo, ao ouvirem e serem ouvidos, apoiarem e serem apoiados. Isso se torna possível quando o facilitador descentraliza o processo grupal, promovendo interações centradas no 
grupo e não em si mesmo, e favorecendo a coesão grupal.

Além da análise das teorias de grupo que influenciam essas propostas, a análise da composição grupal e o processo de seleção e de preparação dos clientes permitem compreender, mesmo que indiretamente, a visão de grupo sustentada por esses autores. Assim, os grupos que Metcalf coordena são homogêneos no sentido dos problemas que levaram os clientes para a terapia. É assim que ela descreve grupos para comportamentos fora de controle ou para pessoas com transtornos alimentares, por exemplo. Esses problemas poderão ser redescritos depois, mas, inicialmente, definem o tipo de grupo que foi formado. Sharry, por outro lado, afirma que o ideal na composição do grupo é que os clientes sejam similares uns aos outros na medida necessária para que a coesão grupal possa ser criada, mas que sejam diferentes o suficiente de maneira que exista a possibilidade de aprenderem entre si. Ele demonstra ainda a preocupação com a criação de uma identidade positiva para o grupo.

Ambos os autores fazem entrevistas com os clientes antes de o processo se iniciar. Metcalf as chama de sessão de avaliação, nas quais procura preencher uma entrevista de admissão junto ao cliente, com o objetivo de se certificar de que "a decisão de participar da terapia de grupo é um reflexo da percepção do cliente de que ele quer, precisa e esperase que faça as coisas diferentemente na vida" (1998, p. 54), já começando nesse momento a se referir à razão de o cliente buscar ajuda como externa a ele, o problema, além de começar um esforço no sentido de estabelecer metas. Sharry, por sua vez, faz entrevistas de triagem e preparação, nas quais o grupo será apresentado para o cliente, em termos de seus objetivos e métodos, além de essa ser uma chance para o facilitador já destacar as mudanças positivas que ocorrem na vida daquela pessoa, que poderão ser usadas durante o processo como base para a construção de mudanças. Ele enfatiza ainda a importância de o facilitador selecionar participantes para o grupo que não apenas possam se beneficiar dele mas que também possam beneficiar os outros membros.

Assim, é possível identificar que as visões de grupo dos dois autores diferem, e, a partir disso, também suas posturas no trabalho com os grupos. Sharry (2001) enfatiza em seu trabalho os aspectos que se referem ao grupo como entidade e às possibilidades de ele, como tal, se mover junto tanto em direção às metas dos membros individuais quanto às metas grupais, enfatizando a coesão e a construção da auto-gestão. Metcalf (1998), por outro lado, enfatiza o papel do indivíduo no grupo e como ele pode beneficiar-se ao participar. Contudo, de forma semelhante, em nenhum dos dois autores há uma teorização sobre o grupo e seu funcionamento. Enquanto Metcalf parecer tomar o grupo como dado, não requerendo uma discussão sobre suas formas de funcionamento, Sharry opera uma leitura do grupo de forma simplista e pouco dinâmica, não aprofundando uma discussão sobre a especificidade grupal nessa forma de terapia focada na solução.

\section{Considerações finais}

Este estudo teórico permitiu vislumbrar algumas possibilidades da utilização da terapia focada na solução em contextos grupais. Além de apresentar esse modelo de terapia, foi possível analisar de que modo suas contribuições foram incorporadas em duas diferentes propostas de sua utilização no campo grupal. De forma geral, constatamos a viabilidade de usar algumas ferramentas técnicas da terapia focada na solução na prática grupal da mesma forma que são utilizadas no contexto individual ou familiar. Em uma análise crítica, podemos considerar 
que as propostas analisadas apresentam certo caráter pragmático, enfatizando a tradução técnica das contribuições da terapia focada na solução, ou seja, pareceu haver um privilégio sobre os procedimentos interventivos, sendo pouco elaboradas as fundamentações teóricas que sustentariam tal prática grupal. Tal efeito pode ter sido gerado seja pela filiação original dos autores ao campo da terapia familiar, que não os sensibilizaria para as especificidades do grupo, seja pelo estilo clínico das obras analisadas, pautado nas suas experiências pessoais como terapeutas, o que não exige uma sistematização empírica ou, na maior parte das vezes, a explicitação ou o desenvolvimento dos fundamentos teóricoepistemológicos.

Esse viés ameaça ocultar as marcas pósmodernas dessa terapia, dando margens a que ela seja confundida com perspectivas estratégicas e objetivistas que não contemplam o caráter construído do problema e do sistema terapêutico. Da mesma forma, ele não permitiu que fosse realizada uma discussão sobre os desafios de utilização do vocabulário e das técnicas da terapia focada na solução nas práticas grupais, o que gera uma apropriação não problemática e não problematizadora daquelas contribuições ao campo grupal.

Assim, apesar das possibilidades de utilização da terapia focada na solução em contextos grupais, a análise das dificuldades presentes nessa empreitada, somada à escassez de literatura, nos convida a continuar investigando o tema para seu aprimoramento e desenvolvimento teórico e técnico, visando a construir uma nova forma de prática grupal. 


\section{Emerson Fernando Rasera}

Doutor em Psicologia pela Universidade de São Paulo e docente da Universidade Federal de Uberlândia, Uberlândia - MG - Brasil.

E-mail: emersonrasera@gmail.com

\section{Pedro Pablo Sampaio Martins}

Mestrando em Psicologia pela Universidade de São Paulo, Ribeirão Preto - SP - Brasil.

E-mail: pedropablomartins@gmail.com

\section{Endereço para envio de correspondência:}

Instituto de Psicologia da Universidade Federal de Uberlândia. Avenida Pará, 1720, Campus Umuarama Bloco 2C, Sala 2C 47. CEP: 38405-320. Uberlândia, MG.

Recebido 14/02/2011, Aprovado 16/01/2013.

Banks, R. (2005). Solution-focused group therapy. Journal of Family Psychotherapy, 16(1-2), 17-21.

Berg, I., \& de Shazer, S. (1993). Making numbers talk: Language in therapy. In S. Friedman (Ed.). The New Language of Change (pp. 5-24). New York: The Guilford Press.

de Shazer, S. (1985). Keys to solution in brief therapy. New York: W. W. Norton e Company.

de Shazer, S. (1988). Clues: Investigating solutions in brief therapy. New York: W. W. Norton e Company.

de Shazer, S. (1991). Putting difference to work. New York: W. W. Norton e Company.

de Shazer, S. (1994). Words were originally magic. New York: W. W. Norton e Company.

Erickson, M., Rossi, E., \& Rossi, S (1976). Hypnotic Realities. The Induction of Clinical Hypnosis and Forms of Indirect Suggestion. New York: Irvington.

Fiske, H., \& Zalter, B. (2005a). A solution-focused group message. Journal of Family Psychotherapy, 16(1-2), 123-125.

Fiske, H., \& Zalter, B. (2005b). Group gift exercise. Journal of Family Psychotherapy, 16(1-2), 131-133.

Froerer, A. S., Smock, S. A., \& Seedall, R. B. (2009). Solutionfocused group work: Collaborating with clients diagnosed with HIV/AIDS. Journal of Family Psychotherapy, 20(1), 13-27.

Grandison, P. (2007). A combined approach: Using eye movement desensitisation and reprocessing (EMDR) within a framework of solution focused brief therapy. Educational and Child Psychology, 24(1), 56-64.

Gergen, K. J., \& Warhuus, L. (2001). Terapia como construção social: características, reflexões, evoluções. In M. M. Gonçalves \& O. F. Gonçalves (Orgs.). Psicoterapia, discurso e narrativa: a construção conversacional da mudança (pp. 27-64). Coimbra: Quarteto.
LaFountain, R. M. (1996). Social interest: A key to solutions. Individual Psychology: Journal of Adlerian Theory, Research \& Practice, 52(2), 150-157.

McCollum, E. E., Trepper, T. S., \& Smock, S. (2003). Solutionfocused group therapy for substance abuse: Extending competency-based models. Journal of Family Psychotherapy, 14(4), 27-42.

Metcalf, L. (1998). Solution focused group therapy: Ideas for groups in private practice, schools, agencies, and treatment programs. New York: The Free Press.

Nelson, T. S., \& Kelley, L. (2001). Solution-focused couples group. Journal of Systemic Therapies, 20(4), 47-66.

Newsome, W. S. (2004). Solution-focused brief therapy groupwork with at-risk junior high school students: Enhancing the bottom line. Research on Social Work Practice, 14(5), 336-343.

O'Hanlon, W. H., \& Davis, M. W. (1994). Em busca de soluções. Campinas, SP : Editorial PSI II.

Quick, E. K., \& Gizzo, D. P. (2007). The "doing what works" group: A quantitative and qualitative analysis of solution-focused group therapy. Journal of Family Psychotherapy, 18(3), 65-84.

Sharry, J. (2001). Solution-focused groupwork. London: SAGE Publications.

Smock, S. A., Trepper, T. S., Wetchler, J. L., McCollum, E. E., Ray, R., \& Pierce, K. (2008). Solution focused group therapy for level 1 substance abusers. Journal of Marital and Family Therapy, 34(1), 107-120.

Springer, D. W., \& Orsbon, S. H. (2002). Families helping families: Implementing a multifamily therapy group with substanceabusing adolescents. Health \& Social Work, 27(3), 204-207.

White, M., \& Epston, D. (1990). Narrative means to therapeutic ends. New York: Norton.

Zimmerman, T. S., Prest, L. A., \& Wetzel, B. E. (1997). Solutionfocused couples therapy groups: An empirical study. Journal of Family Therapy, 19(2), 125-144. 